\title{
Implantação do Programa Seguro-Emprego e saúde dos trabalhadores na indústria automobilística
}

\author{
Employment-Insurance Program implantation and workers' health at \\ automotive industry
}

Leonardo Dresch Eberhardt1, José Augusto Pina', Eduardo Navarro Stotz'

DOI: 10.1590/0103-1104201912305

RESUMO O objetivo do artigo foi analisar a implantação do Programa Seguro-Emprego (PSE) em relação à saúde dos trabalhadores nas montadoras de autoveículos do ABC. A metodologia incluiu pesquisa documental em acordos coletivos de trabalho, legislação, documentos de entidades sindicais e empresariais. Em 2015, o PSE foi lançado pelo governo como resposta à crise econômica, permitindo redução de até $30 \%$ da jornada de trabalho e de salário. Apesar dos questionamentos de grupos sindicais e da resistência operária nas montadoras, a maioria do sindicalismo apoiou a implantação do Programa. Os resultados da pesquisa apontaram o PSE como parte de um novo ciclo de expansão e transformações produtivas na indústria automobilística, ampliando e aprofundando a intensificação do trabalho como forma de geração do desgaste operário. O PSE participa da estratégia empresarial para manter o emprego mais produtivo, selecionando os operários que se manterão no emprego e excluindo trabalhadores considerados de 'baixo desempenho' e os 'compatíveis' (com redução da capacidade laboral). A inclusão do Programa na reforma trabalhista torna-o alternativa permanente para utilização pelas empresas. Portanto, trata-se de tema relevante para as pesquisas e ações em saúde coletiva e saúde do trabalhador.

PALAVRAS-CHAVE Política pública. Recessão econômica. Emprego. Sindicatos. Relações trabalhistas.

1 Fundação Oswaldo Cruz (Fiocruz), Escola Nacional de Saúde Pública Sergio Arouca (Ensp) - Rio de Janeiro (RJ), Brasil. leonardodeberhardt@gmail. com
ABSTRACT The aim of this article was to analyze the implementation of the Employment-Insurance Program (PSE) in relation to the workers' health in the ABC automotive industry. The methodology included documentary research in collective labor agreements, legislation, union and corporate documents. In 2015, the PSE was launched by the government as a response to the economic crisis, allowing up to 30\% reduction in working hours and wages. Despite questions from trade union groups and workers' resistance at the automakers, most unionism supported the implementation of the Program. The survey results pointed to the PSE as part of a new cycle of expansion and productive transformations in the automobile industry, expanding and deepening the intensification of work as a way of generating worker wear. PSE participates in the business strategy to maintain more productive employment by selecting workers who will remain in employment and excluding 'low performers' and 'compatible' workers (with reduced work capacity). The inclusion of the Program in labor reform makes it a permanent alternative for use by companies. Therefore, it is a relevant theme for research and actions in collective health and worker's health.

KEYWORDS Public policy. Economic recession. Employment. Labor unions. Labor relations. 


\section{Introdução}

A economia mundial viveu profunda crise, a partir de 2008, que desencadeou uma nova onda de transformações produtivas, alterações na política estatal com incremento das medidas de austeridade e perda de direitos sociais, inclusive decorrentes de mudanças na legislação trabalhista e previdenciária em diversos países da Europa. Os efeitos da crise e das medidas para retomada do crescimento econômico são sentidos ainda hoje em diferentes sociedades, ainda que de modo desigual e particular em cada país.

No Brasil, após o aumento de 7,5\%, do produto interno bruto, em 2010, a desaceleração do crescimento econômico entre 2011-2014 foi seguida de intensa e prolongada recessão nos anos de 2015-2016. O desemprego, em queda até 2014, elevou-se enormemente e alcançou 14,2 milhões de trabalhadores no primeiro trimestre de 2017. A queda do emprego industrial foi ainda mais prolongada: de outubro de 2011 até o primeiro semestre de 20171,2.

A crise impulsionou outro ciclo de mudanças no processo de produção, especialmente a aceleração da integração nas chamadas 'cadeias globais de valor', formações econômicas em que as etapas do processo produtivo são dispersas em diferentes locais do planeta ${ }^{3(7)}$. Em 2011, o Governo Federal anunciou o Plano Brasil Maior, cujos objetivos incluíam a melhoria da participação das atividades de alta produtividade e tecnologia no âmbito das cadeias globais de valor. O setor automotivo, considerado prioritário, foi o foco de várias medidas de estímulo à produtividade e tecnologia, entre elas, o Inovar-Auto, regime automotivo brasileiro vigente até 2017 e que, em 2018, foi renovado por mais 15 anos com a instituição do Programa Rota $2030^{4}$.

Nesse contexto, governo, entidades empresariais e sindicais dos trabalhadores tomaram várias iniciativas. Entre elas, estão visitas de delegação brasileira à Alemanha a fim de apreender com o modelo alemão de organização do mercado de trabalho e da produção; a publicação de estudos e propostas pela Confederação Nacional da Indústria $(\mathrm{CNI})^{\mathbf{5}}$; a proposição do Acordo Coletivo Especial (ACE) pelo Sindicato dos Metalúrgicos do ABC (SMABC) ${ }^{6}$, da Central Única dos Trabalhadores (CUT); e, inclusive, a implantação do Programa de Proteção ao Emprego (PPE), em 2015, como política pública para preservação do emprego em conjuntura de recessão econômica.

O PPE foi implantado pela Medida Provisória 680/2015, convertida na Lei ${ }^{\circ}$ 13.189/20157; e, mediante Acordo Coletivo de Trabalho (ACT), permite a redução de até $30 \%$ do salário e jornada de trabalho, por 12 meses, em empresas cujo Indicador Líquido de Empregos (ILE) estiver igual ou inferior a $1 \%$. A redução salarial pode ser compensada em até $50 \%$ pelo Fundo de Amparo ao Trabalhador (FAT). Os trabalhadores submetidos ao programa não podem ser demitidos durante o período de vigência. A estabilidade também se estende pelo prazo de um terço da duração do Programa, após seu término. Em 2017, o PPE teve o nome alterado para 'Programa Seguro-Emprego' (PSE), o prazo de adesão foi ampliado para 31 de dezembro de 2017; e a vigência, para até 24 meses, em prorrogações a cada 6 meses $^{8}$.

Entre setembro de 2015 e abril de 2016, $78,7 \%$ dos trabalhadores submetidos ao PSE eram empregados do setor automobilístico", com destaque para o pioneirismo das montadoras da Região do ABC, em São Paulo, na incorporação do PSE à gestão da produção e da força de trabalho no âmbito da negociação coletiva entre empresa e sindicato.

Para Laurell10, em perspectiva histórica e tendo por referência os países latino-americanos, os períodos de crise e recessão econômica adquirem grande importância para a saúde coletiva. Primeiro, acarretam o aumento da pauperização dos trabalhadores, expressa na redução salarial, na elevação do desemprego, do emprego informal e na redução de políticas sociais; segundo, promovem transformações nos processos de produção, inclusive 
pela maior internacionalização da economia; terceiro, promovem a aplicação de políticas econômicas que restringem os gastos sociais dos governos até o reforço da privatização de serviços sociais como os de saúde; e, quarto, alteram as condições da ação reivindicativa e política das classes trabalhadoras, especialmente em razão de o alto desemprego ampliar a insegurança no emprego e as dificuldades para defesa das condições de vida, trabalho e saúde. Esse cenário se manifesta, por exemplo, nos resultados de estudos recentes sobre o impacto de períodos de crise e recessão na saúde. Há evidências de que a crise está relacionada com o aumento da ocorrência de agravos à saúde mental - como ansiedade e depressão - e, especialmente nos países da periferia do capitalismo, com o aumento das taxas de mortalidade infantil e de mortalidade por causas específicas - como doenças cardiovasculares, infecções respiratórias, cirrose hepática, suicídios e homicídios ${ }^{\text {11-13 }}$.

Por se tratar de uma política pública de resposta à crise econômica com impacto na produção e no emprego, o PSE adquire importância para a saúde do trabalhador. Assim, o objetivo deste estudo é analisar a implantação do PSE na indústria automobilística em sua relação com a saúde dos trabalhadores. Para tanto, serão avaliadas: a) a efetividade do Programa para assegurar o emprego; b) a implantação do PSE no que se refere à produção/processo de trabalho; c) as posições dos atores sociais envolvidos - do governo, do empresariado e, especialmente, do movimento sindical e da ação operária ante o PSE; d) as implicações desse processo na saúde dos trabalhadores.

\section{Metodologia}

A análise está ancorada na perspectiva da determinação histórica e social do processo saúde-doença, particularmente nas relações entre produção e desgaste operário ${ }^{14}$. Não se pretende trazer as implicações na saúde em termos de perfis epidemiológicos, uma vez que as mudanças da produção e do trabalho em que o PSE está inserido não necessariamente adquirem expressões imediatas no processo saúde-doença dos trabalhadores. O PSE e sua participação nas transformações na produção, no processo de trabalho e na dinâmica do mercado de trabalho marcam as formas sociais, biológicas e psíquicas dos trabalhadores por longo tempo, e não apenas no presente ou no futuro imediato. Assim, neste artigo, as implicações na saúde dos trabalhadores estão centradas na produção social do desgaste operário ${ }^{14}$, em que vai se gestando o processo de adoecimento antes mesmo de emergir suas expressões patológicas.

O método utilizado para coleta de dados foi a pesquisa documental, com base em três fontes: 1) ACT firmados entre o SMABC e as montadoras automobilísticas, entre 2015 e 2016, de acesso público no portal on-line do Ministério do Trabalho e Emprego (MTE); 2) legislação e material produzido durante a tramitação e a implantação do PSE; e 3) documentos das entidades empresariais, centrais sindicais e sindicatos a respeito do PSE, disponíveis em seus portais on-line.

A opção pela pesquisa documental se justifica em virtude da possibilidade de os registros produzidos pelos atores (Governo Federal, Congresso Nacional, entidades empresariais e de trabalhadores) durante a tramitação e a implantação do PSE contribuírem para sua avaliação. Além disso, os documentos consultados possuem informações abrangentes sobre sua implantação.

\section{Resultados}

\section{PSE pelas perspectivas do governo, do empresariado e dos sindicatos}

A Medida Provisória nº 680/15, que trata da implantação do PSE, tramitou no Congresso Nacional entre julho e novembro de 2015, culminando na Lei ${ }^{\circ} 13.189$. Os objetivos explícitos do PSE são: 
I - possibilitar a preservação dos empregos em momentos de retração da atividade econômica; II - favorecer a recuperação econômico-financeira das empresas; III - sustentar a demanda agregada durante momentos de adversidade, para facilitar a recuperação da economia; IV - estimular a produtividade do trabalho por meio do aumento da duração do vínculo empregatício; e $\mathrm{V}$ - fomentar a negociação coletiva e aperfeiçoar as relações de emprego ${ }^{\mathbf{7}(1)}$.

Algumas exigências são impostas pela legislação às empresas que aderem ao PSE: esgotamento do Banco de Horas (BH); proibição de demissão arbitrária ou sem justa causa durante o período de estabilidade; proibição de exercer contratação de empregados para executar atividades desempenhadas por empregado abrangido pelo Programa, com algumas exceções; proibição de realização de horas extraordinárias. Contudo, a lei não faz menção à utilização de modalidades de compensação de horário como o $\mathrm{BH}$ durante a vigência do Programa.

Diversos atores sociais se envolveram no debate acerca da implantação do PSE, antes e durante a tramitação da medida provisória do Congresso Nacional. Destacam-se três posicionamentos: do empresariado, do governo e do movimento sindical.

Do ponto de vista do empresariado, o PSE seria uma alternativa de flexibilização do trabalho vantajosa em relação àquelas até então disponíveis, como o layoff - dispositivo utilizado pelas empresas para suspender temporariamente o contrato de trabalho e a realização de cursos de qualificação nesse período, com bolsas pagas pelo FAT. Para as entidades empresariais, como a CNI, esse dispositivo seria controverso do ponto de vista da legislação, o que causaria uma 'insegurança jurídica' para os empregadores 5 . O PSE reduz os custos salariais e encargos pagos pelas empresas por um período total de 24 meses, bem superior ao do layoff, em que a duração máxima é de 5 meses; e, em caso de sua extensão, o custo com pagamento dos salários dos empregados é exclusivamente da empresa.

Para o governo, o PSE é apresentado como uma alternativa vantajosa em relação ao layoff, pois, ao manter o trabalhador na empresa e recebendo salário, ainda que reduzido, mantém parte da arrecadação com as contribuições incidentes sobre a folha de pagamento, como da Previdência Social e do Fundo Garantia por Tempo de Serviço (FGTS).

O movimento sindical (centrais sindicais e intersindicais) também se posicionou diante do PSE (quadro 1). CUT, Força Sindical (FS) e União Geral dos Trabalhadores (UGT) apoiaram a medida, enquanto Central dos Trabalhadores e Trabalhadoras do Brasil (CTB), Intersindical - Central da Classe Trabalhadora, Intersindical - Instrumento de Luta e Organização da Classe Trabalhadora e Central Sindical e Popular (CSP-Conlutas) foram contra. Os argumentos favoráveis incluíram o PSE como avanço na direção da modernização das relações de trabalho e contribuição para fomentar a inovação e incrementar a indústria brasileira, além da manutenção do emprego e da renda, apesar da redução salarial. A medida também é considerada mais vantajosa e substitutiva ao layoff. Os argumentos contrários da CSP-Conlutas e Intersindicais afirmaram que o PSE acabaria por reduzir os salários e os direitos dos trabalhadores e não protegeria os empregos. A CTB argumentou que a medida não resolveria o problema do desemprego e defendeu a recuperação econômica mediante estímulos ao consumo. 
Quadro 1. Posição das centrais sindicais quanto à proposta do Programa Seguro-Emprego (PSE), 2015

\begin{tabular}{|c|c|c|}
\hline Central Sindical & Posição & Justificativa \\
\hline Central Única dos Trabalhadores (CUT) & Favorável & $\begin{array}{l}\text { O PSE proporciona a preservação de empregos, a criação } \\
\text { de uma indústria inovadora e a modernização das relações } \\
\text { de trabalho no Brasil. }\end{array}$ \\
\hline Força Sindical (FS) & Favorável & $\begin{array}{l}\text { O Programa preserva empregos, é um avanço em relação } \\
\text { ao layoff e onera menos a renda e os direitos dos traba- } \\
\text { Ihadores. }\end{array}$ \\
\hline União Geral dos Trabalhadores (UGT) & Favorável & $\begin{array}{l}\text { O PSE não é solução definitiva para o desemprego, mas é } \\
\text { um avanço em relação às alternativas existentes. }\end{array}$ \\
\hline $\begin{array}{l}\text { Central dos Trabalhadores e Trabalhado- } \\
\text { ras do Brasil (CTB) }\end{array}$ & Contrária & $\begin{array}{l}\text { A medida não resolve o problema do desemprego, pois } \\
\text { seria preciso estimular o consumo para que a economia } \\
\text { voltasse a crescer. }\end{array}$ \\
\hline $\begin{array}{l}\text { Intersindical - Central da Classe Traba- } \\
\text { Ihadora }\end{array}$ & Contrária & $\begin{array}{l}\text { O Programa não soluciona o desemprego e coloca os } \\
\text { trabalhadores e sindicatos à mercê de chantagem empre- } \\
\text { sarial. }\end{array}$ \\
\hline $\begin{array}{l}\text { Intersindical - Instrumento de Luta e } \\
\text { Organização da Classe Trabalhadora }\end{array}$ & Contrária & $\begin{array}{l}\text { O objetivo do PSE é reduzir salários e direitos dos traba- } \\
\text { Ihadores. }\end{array}$ \\
\hline $\begin{array}{l}\text { Central Sindical e Popular (CSP-Con- } \\
\text { lutas) }\end{array}$ & Contrária & $\begin{array}{l}\text { A proposta do PSE teria o 'verniz' da proteção ao emprego, } \\
\text { mas seu sentido é oposto. }\end{array}$ \\
\hline
\end{tabular}

Fonte: Elaboração própria. Portais on-line das centrais sindicais e outros.

A Confederação Nacional dos Trabalhadores da Agricultura (Contag) criticou o Programa por não contemplar os trabalhadores rurais, em função da elevada informalidade do trabalho no campo, da grande quantidade de contratos temporários e do salário muito próximo ao mínimo inviabilizar os acordos coletivos, já que a aplicação da redução salarial acarretaria pagamento inferior ao salário mínimo.

\section{PSE nas montadoras do setor automobilístico no ABC}

Entre as empresas que aderiram ao PSE no último trimestre de 2015, destacam-se as montadoras do setor automobilístico do ABC, em São Paulo. Os ACT que estabelecem o PSE nas três montadoras analisadas (Ford; Volkswagen - VW; e Mercedes-Benz do Brasil - MBB) são firmados por instrumentos normativos específicos, conforme exigência da legislação, mas a negociação para sua implantação abrange outros acordos que tratam de diversos temas, como reajuste salarial, jornada de trabalho, layoff e Planos de Demissão Voluntária (PDV) (quadro 2). Firmados em 2015 e 2016, eles incluem cláusulas com efeitos para os anos seguintes. 
Quadro 2. Acordos Coletivos de Trabalho (ACT) nas montadoras do setor automobilístico do ABC paulista, 2015-2016

\begin{tabular}{|c|c|c|c|c|}
\hline & & Ford & Mercedes & Volkswagen \\
\hline \multirow{4}{*}{ 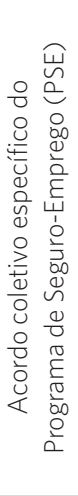 } & Redução salarial & $\begin{array}{l}20 \% \text { com pagamento da metade da } \\
\text { redução pelo FAT. Redução de } 10 \% \\
\text { no } 13 \text { ㅇ salário. Sem efeitos nas férias } \\
\text { e PLR? }\end{array}$ & $\begin{array}{l}\text { 20\% com pagamento da metade da } \\
\text { redução pelo FAT. Perda de 3\% no } \\
\text { 13ㅇsalário, em 2015, e 5\% em } 2016 . \\
\text { Sem efeitos nas férias. }\end{array}$ & $\begin{array}{l}20 \% \text { com pagamento da metade da } \\
\text { redução pelo FAT. Sem efeitos no 13으 } \\
\text { salário, férias e PLR. }\end{array}$ \\
\hline & $\begin{array}{l}\text { Redução da jornada de } \\
\text { trabalho }\end{array}$ & $20 \%$ & $\begin{array}{l}20 \% \text { sobre } 44 \text { horas semanais com } \\
4 \text { horas no } \mathrm{BH}^{4} \text { e rodízio com uma } \\
\text { folga semanal. }\end{array}$ & $\begin{array}{l}20 \% \text { sobre } 42 \text { horas com } 2 \text { horas no } \\
\text { BH e } 2 \text { jornadas adicionais no mês }\end{array}$ \\
\hline & $\begin{array}{l}\text { Quantidade de traba- } \\
\text { Ihadores }\end{array}$ & 3.300 & 8.700 & 9.300 \\
\hline & Duração e período & $\begin{array}{l}9 \text { meses. } \\
\text { De 01/01/2016 até 30/09/2016. }\end{array}$ & $\begin{array}{l}9 \text { meses. } \\
\text { 03/09/2015 até 31/05/2016. }\end{array}$ & $\begin{array}{l}6 \text { meses. Prorrogado por mais } 6 \\
\text { meses. } \\
\text { 01/10/2015 até 31/10/2016. }\end{array}$ \\
\hline \multirow{3}{*}{ 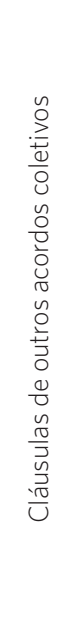 } & Reajuste salarial & $\begin{array}{l}\text { 2015: 0\% INPC } 2 \text {. Abono salarial de } \\
\text { R\$ } 8 \text { mil. } \\
\text { 2016: } 100 \% \text { do INPC mais abono } \\
\text { salarial de } \$ \text { \$ 1,7 mil. }\end{array}$ & $\begin{array}{l}\text { 2015: } 100 \% \text { do INPC. } \\
\text { 2016: } 50 \% \text { do INPC. Abono salarial } \\
\text { de R\$ } 3 \text { mil. }\end{array}$ & $\begin{array}{l}\text { 2015: 0\% do INPC. Abono salarial } \\
\text { de } \$ \text { \$ 6,372,00. } \\
\text { 2016: } 100 \% \text { do INPC. }\end{array}$ \\
\hline & Layoff & $\begin{array}{l}\text { Antes e após o PSE } \\
971 \text { operários, entre out./2015 e } \\
\text { fev./2017. }\end{array}$ & $\begin{array}{l}\text { Antes e após o PSE } \\
\text { 2015: } 500 \text { operários. } \\
\text { 2016: } 1.200 \text { operários de out./2016 } \\
\text { a dez./2017, em três turmas de } 400 \\
\text { a cada } 5 \text { meses. }\end{array}$ & $\begin{array}{l}\text { Antes e após o PSE } \\
\text { 2015: } 2.640 \text { operários ( } 240 \text { entre } \\
\text { jun./nov. e } 2.400 \text { entre jul./dez.). } \\
\text { Após, inclusão no PSE. } \\
\text { 2016: } 3 \text { mil operários. }\end{array}$ \\
\hline & Demissão por PDV & $\begin{array}{l}\text { 2016: } 300 \text { trabalhadores: aposen- } \\
\text { tados, próximos da aposentadoria, } \\
\text { considerados 'baixo desempenho' } \\
\text { (incluídos no 'PDM'3) e compatíveis. } \\
\text { Cláusula de quitação geral. }\end{array}$ & $\begin{array}{l}\text { 2015: trabalhadores compatíveis que } \\
\text { estavam em layoff. } \\
2016: 1.400 \text { trabalhadores, dos quais } \\
400 \text { compatíveis. } \\
\text { Cláusula de quitação geral. }\end{array}$ & $\begin{array}{l}\text { 2015: operários em layoff não incluí- } \\
\text { dos no PSE como os da manutenção. } \\
\text { 2016: } 1.300 \text { trabalhadores até o total } \\
\text { de } 3.600 \text { até } 2021 . \\
\text { Elegíveis: compatíveis e 'baixo de- } \\
\text { sempenho'. } \\
\text { Cláusula de quitação geral. }\end{array}$ \\
\hline
\end{tabular}

Fonte: Elaboração própria. Sistema Mediador - Ministério do Trabalho e Emprego (MTE) e outros.

1Participação nos Lucros e Resultados; 2Índice Nacional de Preços ao Consumidor; ${ }^{3}$ Programa de Melhoria do Desempenho; ${ }^{4}$ Banco de Horas.

O contexto anterior à implantação do PSE nas montadoras incluiu a queda da produção e a utilização de férias coletivas, BH e layoff pelas empresas. Além disso, as empresas lançaram mão dos PDV - ferramenta extrajudicial utilizada para a demissão de grandes quantidades de trabalhadores mediante acordo entre sindicato e empresa e recebimento de compensação financeira pelo demitido. Nesse contexto, as ameaças e as demissões provocaram um clima de 'tensão' para os trabalhadores. Os operários procuraram resistir às demissões, com greves na VW, MBB e Ford.

As empresas anunciavam a necessidade de demissões em massa, e o sindicato negociava a implantação do PSE. A tensão no meio operário pela ameaça de demissão foi registrada no jornal 'Tribuna Metalúrgica' do SMABC ${ }^{15(3)}$ por inúmeros relatos de trabalhadores das montadoras:

Estava cheio de planos e agora estou há 11 meses na incerteza do layoff. [...] todos nós aqui temos uma família que depende da gente, com contas para pagar, saúde para manter, força e coragem para continuar trabalhando; [ou ainda da operária no seu terceiro layoff]: A sensação para quem está vendo essa luta de fora é que a gente não trabalhava o suficiente e merecíamos estar aqui. É exatamente o contrário. [...] A gente pode ser soldado ferido, mas aqui não tem soldado morto. 
Na MBB, a negociação para implantação do PSE já havia se iniciado antes mesmo da regulamentação do Programa. No início de julho de 2015, os operários rejeitaram, com ampla maioria ( $73,8 \%$ dos 7.559 votantes), a proposta apresentada por sindicato e empresa de redução de $20 \%$ de jornada e de $10 \%$ de salário, além de reajuste salarial de metade do Índice Nacional de Preços ao Consumidor (INPC) em maio de 2016, do congelamento da progressão salarial até o final de 2016 e da abertura de PDV para aposentados e trabalhadores com problemas de saúde e redução da capacidade laboral em decorrência de acidente ou doença, comumente chamados de 'compatíveis'. O trabalhador compatível de etiologia relacionada com o trabalho possui estabilidade no emprego até a aposentadoria, segundo a convenção coletiva de trabalho nas montadoras da indústria automobilística da Região do ABC.

A resistência operária ao PSE foi enfrentada pela empresa com o anúncio de 1.500 demissões, ainda com os trabalhadores em período de licença remunerada no mês de agosto de 2015. Com a ameaça de demissão, o sindicato convocou os trabalhadores à greve que durou uma semana, finalizada com a suspensão das demissões e com a recuperação do acordo para implantação do PSE anteriormente recusado pelos operários. O PSE foi apresentado por sindicato e empresa como a única alternativa às demissões, já que os outros instrumentos utilizados (BH, layoff etc.) foram 'esgotados', não se revelando suficientes.

Na Mercedes, a jornada de trabalho de 44 horas semanais para grande parte dos trabalhadores inclui 4 horas computadas para o BH. O PSE foi implantado nessa empresa com um rearranjo produtivo e manutenção do $\mathrm{BH}$. A redução de $20 \%$ da jornada do PSE foi aplicada sobre as 44 horas, e não sobre 40 horas (sem BH), da seguinte forma: uma folga por semana, em dia determinado segundo o rodízio de grupos de trabalhadores em cada setor nas áreas produtivas. Ou seja, um número menor de operários manteve o funcionamento ininterrupto da produção em cada dia da semana com uma jornada diária 'normal' ampliada pelo $\mathrm{BH}$.

Arranjo similar ocorreu na VW com jornada de 42 horas semanal, em que duas horas foram para o BH. Além disso, foi acordada a realização de horas extras com duas jornadas adicionais por mês, aos sábados, durante a vigência do PSE.

No período analisado, na Ford, VW e MBB, o layoff foi utilizado antes e depois do período de vigência do PSE ou mesmo durante, nos casos da Ford e VW. Entre 2015 e 2017, mais 5 mil trabalhadores tiveram seus contratos de trabalho suspensos nas três montadoras. Além disso, as férias coletivas e as licenças remuneradas continuaram a ser utilizadas.

Após a vigência e o término da estabilidade concedida pelo PSE, as empresas efetivaram demissões por meio de PDV em negociação com o sindicato: na Ford, 300 demissões em 2016; na MBB, 1.400 demissões em 2016; e na VW, previsão de 3.600 demissões até 2021, sendo 1.300 efetivadas em 2016. Nas três empresas, os PDV foram direcionados especialmente para trabalhadores compatíveis, aposentados ou próximos da aposentadoria e para trabalhadores considerados como 'baixo desempenho'.

Outros temas negociados entre empresas e sindicato simultaneamente aos acordos coletivos do PSE tratam da modernização das fábricas e da introdução de novos produtos. Essas empresas investiram em robotização, mesmo com a forte queda da produção (-41,25\%), do emprego (-29,47\%) e da produtividade (-31,68\%) no período 2014-2016. Por exemplo, até o final de 2017, a VW instalou 373 novos robôs no setor de solda na fábrica de São Bernardo do Campo para produção de dois novos modelos de carro. Outras áreas, como pintura, gravação de chassi e medição de carrocerias, também receberam novos robôs. A MBB, por sua vez, inaugurou uma nova linha de produção de caminhões no início de 2018, concebida sob o conceito da chamada 'indústria 4.0'. As inovações incluem 
a conectividade em nuvem pelas máquinas/ robôs, veículos autoguiados para transporte de peças e componentes e flexibilidade da linha para produção de todos os caminhões da marca. Essas mudanças permitiram reduzir em $15 \%$ o tempo de produção de caminhões.

\section{Discussão}

A redução de jornada e de salário proporcionada pelo PSE permite às empresas avaliar a produtividade do trabalho, a porosidade do processo de valorização ${ }^{\mathbf{1 6}}$, os pontos de eficiência/ineficiência da produção - elementos que constituem a nova situação que irá definir o quadro de pessoal em termos de contratação/ demissão futura.

O PSE participa da estratégia empresarial para manter o emprego mais produtivo, selecionando os operários que se manterão no emprego ('núcleo duro') e aqueles que, considerados de baixo desempenho pelas empresas, serão excluídos.

A legislação do PSE estabelece critérios legais para manutenção do emprego durante determinado período e pequenas restrições para contratação/demissão durante sua vigência, mas não coloca nenhuma regulação acerca da dinâmica do processo de produção/trabalho nas empresas, que segue obedecendo à lógica do ciclo econômico, avaliada no nível de estoque, de ociosidade, das horas trabalhadas, da eficiência e redução de custos, da estratégia de mercado nacional, regional e mundial, enfim, da taxa de lucro esperada pelo investimento realizado. Com isso, a implantação do PSE proporciona ampla liberdade às empresas em termos de arranjos produtivos como os que ocorreram na MBB e VW, com manutenção do BH e convocação de horas extras. Também na VW, para recuperar paralisações na produção decorrente de atrasos de fornecedores, o PSE chegou a ser suspenso nos meses de junho e julho de 2016, retornando nos meses seguintes. Propostas de maior flexibilidade à jornada de trabalho durante o PSE, como a permissão de realização de horas extras e compensação da jornada, são apresentadas pelos empresários para revisão do Programa 9 . Como atestam os exemplos da VW e da MBB, essas formas já estão presentes durante sua implantação.

A manutenção do $\mathrm{BH}$ e das horas extras em plena vigência do PSE indica que as montadoras da indústria automobilística mantêm práticas de gestão da produção que prolongam a jornada e intensificam o trabalho ${ }^{\mathbf{1 7}}$, simultaneamente ao aumento da densidade tecnológica em suas plantas de produção.

Como visto, as montadoras investiram em robótica avançada e em mudanças nos processos produtivos ainda durante a recessão econômica. Em termos de robotização, o Brasil tem baixa densidade (10 robôs por 10 mil trabalhadores), enquanto países como Coréia do Sul, Cingapura, Alemanha e Japão possuem índices superiores a 300 robôs por 10 mil trabalhadores. No entanto, nas montadoras automobilísticas aqui instaladas, com um total de 4.653 robôs, a densidade de 436/10 mil em 2017 é comparável e até superior à média dos países citados.

Esses novos processos produtivos possibilitam ampliar a produtividade na perspectiva de um novo ciclo de expansão, no âmbito das cadeias globais de valor e da indústria 4.0. Ao mesmo tempo, propiciam reduzir a porosidade da jornada, tanto pelo acompanhamento do trabalhador durante o tempo de trabalho como por sua maior mobilização física, psíquica e subjetiva durante este tempo; por conseguinte, sinalizam a possibilidade de recrudescimento do desgaste operário $^{\mathbf{1 4}}$. Em outros termos, a implantação do PSE nas montadoras do ABC está inserida em outro ciclo de transformações na produção automobilística, ampliando e aprofundando a intensificação do trabalho na determinação histórica e social do desgaste operário ${ }^{18}$.

As medidas adotadas em resposta à crise econômica sinalizam a retomada mais acelerada da produtividade nas montadoras automobilística. Entre 2017 e 2018, anos marcados por baixo crescimento no conjunto da economia do País, a produção nas montadoras cresceu 
$31,76 \%$; o emprego, apenas $6,22 \%$, enquanto a produtividade elevou-se $23,75 \%{ }^{19}$. A tendência é de que a retomada da expansão da produção e da produtividade aconteça em ritmo acelerado, em descompasso da evolução do emprego.

A implantação do PSE questiona a efetividade dessa política para preservar os empregos em longo prazo. Entre 2014 e 2016, foram cortados 31 mil empregos em todas as montadoras da indústria automobilística no País, mesmo com 42.406 trabalhadores submetidos ao PSE entre 2015 e $2016^{9}$. Como atesta a experiência desse programa nas montadoras do $\mathrm{ABC}$, a estabilidade no emprego para operários submetidos ao PSE é apenas temporária e de curto prazo. Nas três empresas analisadas, transcorrido o período de estabilidade previsto na lei, ocorreram demissões em massa.

A redução do número de trabalhadores parece parte do planejamento internacional das montadoras em resposta à crise, como indica a projeção mundial da VW em cortar 30 mil empregados até 2025, sendo 5 mil no Brasil até 2021, incluindo as 3.600 demissões, parte já efetivada na unidade do ABC. A Ford, por sua vez, anunciou no início de 2019 o fechamento de sua fábrica no $\mathrm{ABC}$.

A introdução do PSE não substituiu o layoff, contrariamente à perspectiva do governo e de parte do sindicalismo. A suspensão temporária do contrato continuou sendo adotada durante e após a vigência do PSE.

Ademais, as demissões e o layoff após o término do PSE nas três montadoras mantêm elevada a insegurança do trabalho para os operários que continuam empregados, exercendo uma pressão adicional para que se submetam aos novos modos de organizar o tempo e a disciplina do trabalho. A tensão gerada nesse processo está na determinação de agravos à saúde física e mental. Estudos realizados com trabalhadores que 'sobreviveram' a demissões em larga escala em períodos de crise econômica encontraram maior prevalência de dor musculoesquelética, distúrbios do sono, humor deprimido, falta de ar e irritações na pele ${ }^{20}$; risco elevado de desenvolver hipertensão arterial21; aumento do uso de drogas psicotrópicas e no absenteísmo por doença ${ }^{22,23}$; risco elevado de morte por todas as causas $-1,5$ vez maior do que trabalhadores que não vivenciaram demissões em larga escala em seus locais de trabalho - e por doenças cardiovasculares - 5,1 vezes nos primeiros 4 anos, e 1,4 vez nos 3,5 anos subsequentes às demissões ${ }^{\mathbf{2 4}}$. Os autores relacionam esses achados ao medo do desemprego, insegurança no trabalho, aumento da pressão por produtividade e aumento das cargas de trabalho ${ }^{21,25-26}$. Também o impacto do desemprego na saúde daqueles que perderam o emprego tem sido indicado na literatura ${ }^{27}$.

No Brasil, alguns sinais da implicação desses processos na saúde mental já parecem emergir. Por exemplo, o número de consultas psiquiátricas cobertas por planos de saúde aumentou 54\% no período 2012-201728.

O direcionamento dos PDV para empregados aposentados, próximos da aposentadoria, considerados como 'baixo desempenho' e, especialmente, compatíveis compõe uma estratégia de exclusão desses trabalhadores do processo de produção ${ }^{18}$. Nos períodos de crise/recessão econômica, a demissão por PDV converteu-se em instrumento das montadoras para contornar a estabilidade até a aposentadoria aos trabalhadores compatíveis. A demissão aparece como ato de vontade individual dos operários. No entanto, segundo o Ministério Público do Trabalho'29, como no PDV envolvendo a demissão de 1.400 operários pela $\mathrm{MBB}$ em 2016, trata-se de forte coação da empresa sobre os trabalhadores demitidos.

Cabe ressaltar que os acordos coletivos de PDV nas três montadoras incluem cláusula de 'quitação geral' do contrato de trabalho do trabalhador à empresa. A concordância da direção sindical dos metalúrgicos do $\mathrm{ABC}$ com esses acordos era anterior e prosseguiu mesmo após decisão do Supremo Tribunal Federal (STF), em 30 de abril de 2015, validar essa cláusula, até então não corroborada nas decisões do Tribunal Superior do Trabalho (TST). Posteriormente, a "reforma trabalhista", 
sancionada pela Lei ${ }^{\circ} 13.467$, de 13 de julho de $2017^{30}$, incluiu a quitação geral nos casos de PDV por convenção ou acordo coletivo sem necessidade de tal cláusula constar no termo de acordo, como determinado no acórdão do STF.

A utilização do PDV para exclusão de trabalhadores com restrição médica e redução de capacidade laboral também acontece em outros setores econômicos. Estudos realizados por Carrijo e Navarro ${ }^{31}$ e Silva $^{32}$ a respeito dos bancários indicaram a existência de ameaça e pressão para adesão ao PDV, sobretudo aos adoecidos por Lesão por Esforço Repetitivo (LER), avaliados pelas empresas como menos produtivos, uma situação similar aos trabalhadores compatíveis da indústria automobilística. Estudos realizados na Finlândia ${ }^{\mathbf{2 4}, \mathbf{2 5}}$ e nos Estados Unidos ${ }^{\mathbf{2 1}}$ encontraram evidências de que, em demissões em larga escala durante crises econômicas, a condição de saúde dos trabalhadores foi determinante para a escolha de quem seria demitido.

Estudos com trabalhadores em montadoras de veículos no Brasil demonstram que os períodos de queda da produção ou de crise econômica constituem momentos em que é sancionada a exclusão de grande número de empregados com esse perfil, enquanto o ciclo de expansão da produção marcado pelo processo de intensificação do trabalho seleciona esses trabalhadores ${ }^{\mathbf{1 8}, \mathbf{3 3}}$. Aqui, o entendimento do processo histórico e social do desgaste operário, pela saúde coletiva, adquire relevância explicativa para melhor compreensão do que, na sociologia, Cardoso ${ }^{34}$ corretamente caracterizou como uso predatório e seletivo da força de trabalho pela indústria automobilística.

O período analisado por Cardoso ${ }^{34}$ (19891995) engloba a crise econômica de 1990-1992, considerado pelo autor como 'divisor de águas excludente' do setor em direção à informalidade: a perda do emprego em uma empresa dessa indústria representou a exclusão do setor para mais de $80 \%$ dos empregados e a eliminação de qualquer emprego formal para metade dos trabalhadores que por ali passaram. $\mathrm{O}$ período também corresponde ao momento em que grandes empresas, com o pioneirismo das montadoras da indústria automobilística, desencadearam seus processos de reestruturação produtiva.

$\mathrm{Na}$ esteira de Cardoso ${ }^{34}$, tal como naquele momento, pode-se levantar a hipótese de que a atual perda do emprego efetivada no setor não se explica unicamente pela diminuição líquida de postos de trabalho decorrentes de novo ciclo de incorporação tecnológica e organizacional. É bem provável que essa redução esteja em curso. A expulsão de grandes contingentes de trabalhadores da indústria automobilística na direção da informalidade, possivelmente, será mantida ao longo do desenvolvimento do atual ciclo de transformações produtivas com base na indústria 4.0, que alteram as formas de geração do desgaste operário a merecer a atenção das pesquisas em saúde coletiva. Tanto mais pelo contexto atual das mudanças produtivas estarem acompanhadas de mudanças políticas na direção da maior liberdade das empresas na utilização da força de trabalho, favorecida pela ampliação da terceirização e da reforma trabalhista, com impacto negativo na proteção social e enfraquecimento da organização coletiva dos trabalhadores ${ }^{35}$.

Em relação ao posicionamento das centrais sindicais, CUT, FS e UGT apoiaram o PSE como medida de proteção do emprego e mais avançada em relação ao layoff. Vale observar a maior aproximação da CUT e da FS ao entendimento do PSE como política para modernização das relações de trabalho e viabilização dos ganhos de produtividade com inovação na produção. Embora contrária ao Programa, a crítica da CTB está centrada no possível agravamento da queda do consumo decorrente da redução salarial e, com isso, inviabilização do desenvolvimento econômico pressuposto como de interesse comum entre capital e trabalho. Por sua vez, CSP-Conlutas e as duas Intersindicais centram a crítica ao PSE no aumento da lucratividade empresarial pela redução salarial e de direitos, pode-se dizer, baseada no aumento da exploração (mais-valia) absoluta. Além dessa característica, 
ao situar o PSE na dinâmica da produção capitalista, esta análise avançou em compreender esse Programa em termos de seleção do emprego mais produtivo integrado ao aumento da produtividade e intensificação do trabalho, ou seja, da exploração operária baseada na mais-valia relativa. Essa última fornece a base em que se desenvolvem as formas de mais-valia absoluta como redução salarial e extensão da jornada (BH e horas extras). Significa dizer que, nas montadoras da indústria automobilística, o PSE participa das transformações produtivas que caracterizam outras formas concretas de trabalhar e, portanto, do processo de desgaste operário e do perfil epidemiológico dos trabalhadores.

O posicionamento das centrais favoráveis ao PSE, principalmente CUT e FS, além da atuação do SMABC, está orientada pela tentativa de compatibilizar produtividade, emprego e saúde, isto é, a posição "ganha-ganha"36(2). Essa diretriz sindical também está presente nos objetivos do PSE.

A crítica a essa posição sindical está presente e assumiu forma concreta e aberta na recusa inicial ao PSE pela enorme maioria dos operários da MBB. Todavia, a imposição de "terror cego" aos trabalhadores ${ }^{37(33)}$ pela constante ameaça de demissão conjugada à ausência de outra perspectiva de ação sindical atuaram para vencer a resistência operária e para aceitar os acordos do PSE. Trata-se de uma "aceitação não consensual"38(171), portanto, que supõe a crítica e mantém a resistência operária ainda que velada e difusa.

Por fim, o PSE representou um ensaio do que tem sido chamado de "acordado sobre o legislado", componente estrutural da reforma trabalhista. O próprio PSE foi incluído na reforma trabalhista ${ }^{30}$, portanto, é possível afirmar que se constitui alternativa permanente, e não apenas circunscrito aos períodos de crise/recessão econômica, disponível para o uso das empresas de todo e qualquer setor da economia. Em vista disso, deve chamar a atenção das ações em saúde coletiva/saúde do trabalhador, uma vez que os preceitos do PSE mantêm a saúde como um item de negociação, submetida à dinâmica da produção e concorrência capitalista.

Diante da natureza exploratória do estudo, ressalta-se a relevância da realização de pesquisas que ampliem e aprofundem aspectos da determinação histórica e social da saúde dos trabalhadores relacionados com os períodos de crise e retomada do crescimento econômico. Por exemplo, estudos etnográficos com grupos de trabalhadores que perderam emprego e com aqueles que continuam empregados em empresas em expansão pós-recessão e em empresas em declínio; ou epidemiológicos, com a utilização de séries temporais articulando bases de dados das áreas do trabalho, previdência social e saúde.

\section{Colaboradores}

Eberhardt LD (0000-0002-8284-1668)* contribuiu para o delineamento do estudo, a coleta, análise e interpretação dos dados, a elaboração de versões preliminares, a redação final do artigo e a aprovação da versão final a ser publicada. Pina JA (0000-0003-32042240)* e Stotz EN (0000-0002-7021-398X)* contribuíram para o delineamento do estudo, a revisão crítica do artigo e a aprovação da versão final a ser publicada. 


\section{Referências}

1. Instituto Brasileiro de Geografia e Estatística. Pesquisa Industrial Mensal de Emprego e Salário [internet]. IBGE, 2015 [acesso em 2018 mar 11]. Disponível em: ftp://ftp.ibge.gov.br/Industrias_ Extrativas_e_de_Transformacao/Pesquisa_Industrial_Mensal_de_Emprego_e_Salario/Comentarios/ pimes_201512comentarios.pdf.

2. Instituto Brasileiro de Geografia e Estatística [internet]. 2018 [acesso em 2018 mar 13]. Disponível em: https://www.ibge.gov.br/.

3. Oliveira ITM, Carneiro FL, Silva Filho EB, organizadores. Cadeias globais de valor, políticas públicas e desenvolvimento. Brasília, DF: IPEA; 2017.

4. Brasil. Lei ${ }^{0} 13.755$, de 10 de dezembro de 2018. Estabelece requisitos obrigatórios para a comercialização de veículos no Brasil; institui o Programa Rota 2030 - Mobilidade e Logística; e dá outras disposições. Diário Oficial da União. 11 Dez 2018.

5. Eichhorst W, Marx P, Pastore J. Crises econômicas e flexibilidade no trabalho. Os casos da Alemanha e do Brasil [internet]. São Paulo: CNI; Bonn: IZA, 2011 [acesso em 2017 set 17]. Disponível em: http://ftp.iza. org/dp6137_BRA.pdf.

6. Sindicato dos Metalúrgicos do ABC. Acordo Coletivo Especial - ACE [internet]. São Bernardo do Campo: SMABC; 2011 [acesso em 2018 mar 12]. Disponível em: http://www.smabc.org.br/ace/.

7. Brasil. Presidência da República. Lei no ${ }^{\circ} 13.189$, de 19 de novembro de 2015. Institui o Programa de Proteção ao Emprego - PPE. Diário Oficial da União. 20 Nov 2015. [acesso em 2019 jan 8]. Disponível em: http://www.in.gov.br/web/dou/-/lei-no-13-189-de19-de-novembro-de-2015-30175261.

8. Brasil. Presidência da República. Lei no 13.456 , de 26 de junho de 2017. Altera o Programa de que trata a Lei ${ }^{\circ} 13.189$, de 19 de novembro de 2015, para denominá-lo Programa Seguro-Emprego e para pror- rogar seu prazo de vigência. Diário Oficial da União. 27 Jun 2017.

9. Scherer CR, Oliveira T. Programa de proteção ao emprego: uma avaliação preliminar a partir da percepção dos atores sociais participantes. In: Anais do $15^{\circ}$ Encontro Nacional da Associação Brasileira de Estudos do Trabalho; 2017; Rio de Janeiro: ABET; 2017.

10. Laurell AC. Crisis y salud en América Latina. Cuadernos Políticos. 1982; 33:32-45.

11. Giorgi G, Arcangeli G, Mucci N, et al. Economic stress in workplace: the impact of fear the crisis on mental health. Work. 2015; 51(1):135-142.

12. Mucci N, Giorgi G, Roncaioli M, et al. The correlation between stress and economic crisis: a systematic review. Neuropsych. Dis Treat. 2016; 12:983-993.

13. Falagas ME, Vouloumanou EK, Mavros MN, et al. Economic crises and mortality: a review of the literature. Int. J. Clin. Pract. 2009; 63(8):1128-1135.

14. Laurell AC, Noriega M. Processo de produção e saúde: trabalho e desgaste operário. São Paulo: Hucitec; 1989.

15. Sindicato dos Metalúrgicos do ABC. O que dizem os trabalhadores em layoff. Tribuna Metalúrgica [internet]. 2015 maio 28 [acesso em 2019 fev 28]; 3723:1-4. Disponível em: http://www.smabc.org.br/ Interag/tribuna_pdf/\%7B1664B283-34D2-4F418E2A-9A83D6681DDA\%7D_TB_3723\%20lores.pdf.

16. Marx K. O Capital: crítica da economia política. São Paulo: Abril Cultural; 1984. (v. 1).

17. Pina JA, Stotz EN. Intensificação do trabalho e saúde dos trabalhadores: um estudo na Mercedes Benz do Brasil, São Bernardo do Campo, São Paulo. Saúde Soc. $2015 ; 24(3): 826-840$.

18. Pina JA, Stotz EN, Jackson Filho JM. Trabalhador 
"compatível”, fratura exposta no processo de produção da indústria automobilística: intensificação do trabalho e saúde em questão. Cad. Saúde Pública. 2018; 34(7):e00114017.

19. Associação Nacional dos Fabricantes de Veículos Automotores. Anuário da indústria automobilística brasileira 2019 [internet]. São Paulo: ANFAVEA; 2019 [acesso em 2019 fev 28]. Disponível em: http:// www.virapagina.com.br/anfavea2019/.

20. Dragano N, Verde PE, Siegrist J. Organisational downsizing and work stress: testing synergistic health effects in employed men and women. J. Epidemiol. Community Health. 2005; 59:694-699.

21. Modrek S, Cullen MR. Health consequences of the 'Great Recession' on the employed: evidence from an industrial cohort in aluminum manufacturing. Soc. Sci. Med. 2013; 92:105-113.

22. Kivimäki M, Honkonen T, Wahlbeck K, et al. Organisational downsizing and increased use of psychotropic drugs among employees who remain in employment J. Epidemiol. Community Health. 2007; 61:154-158.

23. Vahtera J, Kivimäki M, Pentti J. Effect of organisational downsizing on health of employees. Lancet. 1997; 350:1124-28.

24. Vahtera J, Kivimäki M, Pentti J, et al. Organisational downsizing, sickness absence, and mortality: 10-town prospective cohort study. BMJ. 2004; 328:1-5.

25. Kivimäki M, Vahtera J, Elovainio M, et al. Human costs of organizational downsizing: comparing health trends between leavers and stayers. Am. J. Community Psychol. 2003; 32 (1/2):57-67.

26. Modrek S, Cullen MR. Job insecurity during recessions: effects on survivors' work stress. BMC Public Health. 2013; 13:929.

27. Seligmann-Silva E. Trabalho e desgaste mental: o direito de ser dono de si mesmo. São Paulo: Cortez; 2011.

28. Agência Nacional de Saúde Suplementar. Mapa Assistencial da Saúde Suplementar 2017. Rio de Janeiro: ANS; 2018.

29. Brasil. Ministério Público do Trabalho. Mercedes Benz é processada em $\mathrm{R} \$ 140$ mi por demissões discriminatórias. MPT Notícias [internet]. 2017 set 5. [acesso em 2018 mar 13]. Disponível em: http://radio.mpt.gov.br/wps/portal/portal_mpt/mpt/sala-imprensa/mptnoticias.

30. Brasil. Presidência da República. Lei no ${ }^{\circ} 13.467$, de 13 de julho de 2017. Altera a Consolidação das Leis do Trabalho (CLT), aprovada pelo Decreto-Lei ${ }^{\circ} 5.452$, de 1 de maio de 1943, e as Leis $n^{\circ} 6.019$, de 3 de janeiro de 1974, 8.036, de 11 de maio de 1990, e 8.212, de 24 de julho de 1991, a fim de adequar a legislação às novas relações de trabalho. Diário Oficial da União. 14 Jul 2017. [acesso em 2019 jan 8]. Disponível em: http:// www.planalto.gov.br/ccivil_03/_ato2015-2018/2017/ lei/L13467.htm.

31. Carrijo DCM, Navarro VL. LER e planos de demissão voluntária: trajetórias de dor e sofrimento entre bancários. Cad. Psicol. Soc. Trab. 2009; 12(1):151-171.

32. Silva EP. Programas de Demissão Voluntária em uma instituição bancária: da gestão da adesão ao Programa às complexas perdas psicossociais. Rev. Psicol. Org. Trab. 2002; 2(2):143-173.

33. Glina DMR, Rocha LE, Batista ML, et al. Saúde mental e trabalho: uma reflexão sobre o nexo com o trabalho e o diagnóstico, com base na prática. Cad. Saúde Pública 2001; 17:607-16.

34. Cardoso AM. Trabalhar, verbo transitivo: trajetórias ocupacionais de trabalhadores da indústria automobilística. Dados. 1998; 41(4):701-750.

35. Krein JD. O desmonte dos direitos, as novas configurações do trabalho e o esvaziamento da ação co- 
letiva: consequências da reforma trabalhista. Tempo Soc. 2018; 30(1):77-104.

36. Stotz EN, Pina JA. Experiência operária e ciência na luta pela saúde e a emancipação social. Rev. Bras. Saúde Ocup. 2017; 42(e12):1-11.

37. Beynon H. As práticas do trabalho em mutação. In: Antunes R, organizador. Neoliberalismo, trabalho e sindicatos: reestruturação produtiva no Brasil e na
Inglaterra. São Paulo: Boitempo; 1999. p. 9-38.

38. Navarro V. Produção e estado de bem-estar. O contexto político das reformas. Lua Nova. 1993; 28-29:157200.

Recebido em 08/03/2019

Aprovado em 09/09/2019

Conflito de interesses: inexistente

Suporte financeiro: não houve 